\title{
Osteoarticular involvement of brucellosis in pediatric patients: clinical and laboratory characteristics
}

\author{
Dilek Yilmaz Çiftdoğan ${ }^{1,2}$, Selda Aslan ${ }^{3 \oplus}$ \\ ${ }^{1}$ Department of Pediatric Infectious Diseases, İmir Katip Çelebi University, Izmir; ${ }^{2}$ Department of Pediatric Infectious Diseases, \\ Tepecik Training and Research Hospital, Izmir; ${ }^{3}$ Department of Infectious Diseases, Gaziantep Children State Hospital, Gaziantep, \\ Turkey.
}

\begin{abstract}
Background and objectives. The aim of this study was to evaluate the clinical and laboratory characteristics of osteoarticular involvement in children with brucellosis.

Methods. A total of 202 pediatric brucellosis patients were evaluated from April 2012 to August 2013.

Results. Among the 202 patients, 53 (26.2\%) had osteoarticular involvement. In patients with osteoarticular involvement, the mean values of estimated sedimentation rate (ESR) and C-reactive protein (C-RP) were significantly higher than in patients without osteoarticular involvement $(p=0.001, p=0.01$, respectively). The majority of patients with osteoarticular involvement $(n=48,90.6 \%)$ had a higher standard tube agglutination (STA) test titer $(\geq 1 / 640)$ than patients without osteoarticular involvement $(n=69,46.3 \%)(p=0.001)$. The most commonly found osteoarticular involvement was peripheral arthritis. The second most commonly found osteoarticular involvement was sacroiliitis $(n=5,9.4 \%)$. Three patients $(5.7 \%)$ had spondylitis. Only one patient $(1.9 \%)$ had osteomyelitis.
\end{abstract}

Conclusions. Osteoarticular involvement was detected in nearly one of every four childhood brucellosis patients in our study. Brucellosis should be considered as a pre-diagnosis in children with osteoarticular complaints, especially in regions where the disease is endemic.

Key words: Brucellosis, osteoarticular, pediatric.

Brucellosis is a serious public health issue throughout the world; it is of special concern in the Mediterranean region which includes Turkey. ${ }^{1-3}$ Turkey's geographic situation is a risk factor for many infectious diseases. ${ }^{4}$ The yearly incidence rate of this zoonotic disease in Turkey is 23 per 100,000 people. ${ }^{3}$ However, the true incidence rate of brucellosis is not known because underreporting of the disease is believed to be common. Despite being endemic in Turkey, brucellosis remains underdiagnosed

$\otimes$ Dilek Yılmaz Çiftdoğan

drdilekyilmaz@hotmail.com

Received 18th December 2018, revised 1st June 2019, 29th June 2019, accepted 11th November 2019.

This study was presented at the 53rd Turkish Pediatr Congress, 14-18 May 2017, Girne, Turkish Rebuplic of Northern Cyprus. due to non-specific clinical manifestations and laboratory parameters.

Brucellosis is a multisystem disease which may present with a broad spectrum of clinical manifestations. It may mimic other infectious and non-infectious conditions. Fever, sweats, malaise, lethargy, anorexia, and joint pain are the most common complaints in childhood brucellosis. ${ }^{5}$ Osteoarticular involvement has been extensively reported in adults and is also the predominant manifestation of brucellosis in children..$^{5-7}$ Osteoarticular involvement in brucellosis was first reported by Kennedy in $1904 .^{8}$ There are several reports of osteoarticular involvement in brucellosis in adults and children from various regions. ${ }^{2,5-12}$ However, the prevalence and characteristics of osteoarticular involvement in brucellosis are influenced 
by many factors: regional differences, environmental factors, differences in hosts, and the age of the patients. ${ }^{9-12}$

The aim of this study was to evaluate the demographic, clinical, and laboratory characteristics of osteoarticular involvement in children with brucellosis.

\section{Material and Methods}

A total of 202 pediatric patients who had been diagnosed with brucellosis at the Gaziantep State Children Hospital's Department of Pediatric Infectious Diseases were evaluated from April 2012 to August 2013. Among the 202 patients, $53(26.2 \%)$ had some degree of osteoarticular involvement.

The diagnosis of brucellosis was based on the Centers for Disease Control and Prevention's definition, which includes the presence of clinical signs and symptoms with evidence of Brucella spp. invasion in a positive culture or a single high titer against Brucella spp. of $\geq$ 1:160. ${ }^{13}$ Patients who had positive Rose Bengal test results were further tested by the standard tube agglutination test (STA). Seropositivity was defined as an STA titer of 1/160 or more. During the study period, Coombs test and 2-mercaptoethanol agglutination test could not be performed routinely in the laboratory.

Based on the duration of disease, patients were classified as having acute brucellosis $(<3$ months), subacute brucellosis (3-12 months), or chronic brucellosis (> 12 months). Any history of drinking unpasteurized milk, consumption of unpasteurized dairy products and handling animals or animal excretions were recorded. Blood, bone marrow aspirates and synovial fluid samples were not routinely cultured for Brucella spp. Demographic data, clinical manifestations, and outcomes were evaluated. Complete blood count $(\mathrm{CBC})$, erythrocyte sedimentation rate (ESR), C-reactive protein (C-RP), and blood chemistry profile were analyzed.
Peripheral arthritis was defined as pain and the presence of at least two other signs of inflammation of the affected joint, including swelling, restriction of joint movement, heat, and redness. Hip arthritis was defined as pain and a positive flexion-abduction-external rotation (FABER) or Stinchfield test with the presence of the abnormality shown on radiologic examination. Clinically, sacroiliitis was diagnosed as inflammatory pain and functional disability associated with a positive FABER test. The patients with back pain and progressive stiffness of the spine were evaluated for spondylitis. Radiography, computed tomography (CT), or magnetic resonance imaging (MRI) was performed on all patients with clinical signs that suggested sacroiliitis, spondylitis, osteomyelitis, or hip involvement.

All patients were treated with various antimicrobial combinations. The antimicrobial combinations consisted of oral rifampin, oral doxycycline in children $\geq 8$ years old, oral trimethoprim/sulfamethoxazole, intramuscular streptomycin, and intramuscular/intravenous gentamicin. Therapeutic failure was defined as the persistence of symptoms or clinical signs during the antimicrobial combination treatment. Relapse was defined as a recurrence or exacerbation of symptoms and the presence of clinical signs after completion of the antimicrobial combination treatment.

The study was approved by the local ethics committee (no.55-02/05/2013). Informed consent was obtained from all the individual's parents.

Data analysis was performed using the IBM SPSS Statistics ver. 19.0 (IBM Corporation, Armonk, NY, USA) software. We expressed continuous variables as the mean \pm standard deviation (S.D.) with the median, using a Chisquare test to compare proportions. The Fisher's exact test was used for expected frequencies below five in the contingency tables. A one-way analysis of variance (ANOVA) test was used for multiple comparisons. $P$ values $<0.05$ were considered statistically significant. 


\section{Results}

In this study, 202 children with brucellosis were analyzed. Among these patients, 123 $(60.9 \%)$ were male, and 79 (39.1\%) were female. The rate of male patients was significantly higher than female patients $(p<0.05)$. The age distribution of the patients was 1-18 years (mean age $7.37 \pm 4.14$ years). A majority of 188 $(93.1 \%)$ patients were in the acute stages of brucellosis, $11(5.5 \%)$ had subacute brucellosis, and three $(1.4 \%)$ had chronic brucellosis. Among these 202 brucellosis patients, 53 $(26.2 \%)$ had osteoarticular involvement, and their mean age was $10.3 \pm 4.06$ years. However, the mean age of patients without osteoarticular involvement was lower than in patients with osteoarticular involvement (6.34 \pm 3.61 years, $p$ $<0.0001)$. Gender distribution rates of patients with and without osteoarticular involvement were similar. While there was no correlation between gender and osteoarticular involvement $(p>0.05)$, a significant correlation was found between age and osteoarticular involvement $(r=0.43, p=0.001)$. All of the patients with chronic brucellosis $(n=3)$ had osteoarticular involvement. Differences in the distribution of disease classifications based on the duration of disease between patients with and without osteoarticular involvement were statistically significant $(p=0.006)$.

Eight patients with osteoarticular involvement $(15.1 \%)$ had a history of handling animals or animal excretions. Seventeen patients without osteoarticular involvement (11.4\%) had a history of handling animals or animal excretions. None of patients with and without osteoarticular involvement admitted to drinking unpasteurized milk. However, 28 patients with osteoarticular involvement (52.8\%) and 71 patients with osteoarticular involvement $(47.6 \%)$ had a history of ingesting unpasteurized dairy products. There were no significant differences in history of handling animals or animal excretions and a history of ingesting unpasteurized dairy products between patients with and without osteoarticular involvement ( $\mathrm{p}$ $=0.48, \mathrm{p}=0.51$; respectively) .
The specific demographic and clinical characteristics of patients with and without osteoarticular involvement are shown in Table I. The most frequent patient symptoms were fever, malaise, arthralgia, and anorexia. The frequency of fever, malaise, arthralgia, and myalgia were higher in patients with osteoarticular involvement (overall, $p<0.05$ ). The frequency of hepatomegaly, splenomegaly, and lymphadenopathy were similar in patients with and without osteoarticular involvement (overall, $>$ 0.05). Laboratory characteristics and distribution of STA titers of patients with and without osteoarticular involvement are shown in Table II. In patients with osteoarticular involvement, the mean values of ESR and C-RP were significantly higher than in patients without osteoarticular involvement ( $p=0.001, p=0.01$, respectively). The frequency of leukocytosis was higher in patients with osteoarticular involvement ( $p=$ 0.002). However, the frequencies of leukopenia, thrombocytopenia, and anemia were not significantly different between the patients with and without osteoarticular involvement (overall, $p>0.05$ ).

Among all patients, STA titers ranged from $1 / 160$ to $>1 / 1280$ (Table II). The differences of the distribution of the STA titers between patients with and without osteoarticular involvement were statistically significant $(p=0.001)$. The majority of patients with osteoarticular involvement $(n=48,90.6 \%)$ had a higher STA titer $(\geq 1 / 640)$ than patients without osteoarticular involvement $(n=69,46.3 \%)$, and this difference was statistically significant ( $p=$ 0.001).

After the treatment, in 4 patients with ongoing disease symptoms, 2-mercaptoethanol agglutination tests were performed at external laboratory centers. Only one patient's test result was positive. The Coombs test were performed on only 5 patients who had relapsing brucellosis or prolonged active infection. In the study, there were no patients who were negative with Wright test but positive with Coombs test. 
Table I. Demographic and clinical characteristics of patients with and without osteoarticular involvement.

\begin{tabular}{|c|c|c|c|}
\hline & $\begin{array}{c}\text { Patients with } \\
\text { osteoarticular involvement } \\
\qquad(\mathrm{n}=53)\end{array}$ & $\begin{array}{c}\text { Patients without } \\
\text { osteoarticular involvement } \\
\qquad(\mathrm{n}=149)\end{array}$ & $p$-value \\
\hline$\overline{\text { Age }^{*}}$ & $10.3 \pm 4.06$ & $6.31 \pm 3.56$ & 0.001 \\
\hline \multicolumn{4}{|l|}{$\operatorname{Gender}^{* *}(n, \%)$} \\
\hline Male & $36(67.9)$ & $87(58.4)$ & 0.25 \\
\hline Female & $17(32.1)$ & $62(41.6)$ & \\
\hline \multicolumn{4}{|l|}{ Clinical type $e^{* *}$} \\
\hline Acute & $42(95)$ & $143(96)$ & 0.006 \\
\hline Sub-acute & $5(9.4)$ & $6(4)$ & \\
\hline Chronic & $3(5.7)$ & - & \\
\hline Fever** & $48(90.6)$ & $108(72.5)$ & 0.007 \\
\hline Malaise ${ }^{* *}$ & $47(88.7)$ & $96(64.4)$ & 0.001 \\
\hline Anorexia** & $40(75.5)$ & $104(69.8)$ & 0.434 \\
\hline Myalgia** & $63(45.3)$ & $18(28.6)$ & 0.025 \\
\hline Weight loss ${ }^{* *}$ & $19(35.8)$ & $42(28.2)$ & 0.29 \\
\hline Abdominal pain ${ }^{* *}$ & $17(32.1)$ & 55 (36.9) & 0.529 \\
\hline Dyspepsia** $^{* *}$ & $18(34)$ & 47 (31.5) & 0.747 \\
\hline Headache ${ }^{* *}$ & $15(28.4)$ & $36(24.2)$ & 0.552 \\
\hline Night sweats** & $5(9.4)$ & $15(10.1)$ & 0.89 \\
\hline Hepatomegaly** & $8(15.1)$ & $28(18.8)$ & 0.54 \\
\hline Splenomegaly** & $5(9.4)$ & $14(9.4)$ & 0.994 \\
\hline Lymphadenopathy** & $3(5.7)$ & $13(8.7)$ & 0.479 \\
\hline
\end{tabular}

${ }^{*}$ Mean $\pm S D .,{ }^{* *} \mathrm{n}, \%$

Table II. Laboratory characteristics and distribution of STA titers of patients with and without osteoarticular involvement.

\begin{tabular}{|c|c|c|c|}
\hline & $\begin{array}{c}\text { Patients with } \\
\text { osteoarticular involvement }\end{array}$ & $\begin{array}{c}\text { Patients without } \\
\text { osteoarticular involvement }\end{array}$ & $p$-value \\
\hline$\overline{E S R}(m m / h)^{*}$ & $36.3 \pm 14.2$ & $18.6 \pm 12.6$ & 0.001 \\
\hline C-reactive protein $(\mathrm{mg} / \mathrm{dl})^{*}$ & $2.34 \pm 1.72$ & $1.75 \pm 1.46$ & 0.02 \\
\hline Leukopenia $^{* *}$ & $6(11.3)$ & $21(14.1)$ & 0.611 \\
\hline Leukocytosis** $^{* *}$ & $13(24.5)$ & $12(8.1)$ & 0.002 \\
\hline Thrombocytopenia ${ }^{* *}$ & $5(9.4)$ & $14(9.4)$ & 0.994 \\
\hline \multicolumn{4}{|l|}{ STA titer** } \\
\hline $1 / 160$ & $8(5.8)$ & $5(7.9)$ & \multirow{5}{*}{0.001} \\
\hline $1 / 320$ & $13(9.3)$ & $12(19.1)$ & \\
\hline $1 / 640$ & $50(35.9)$ & $21(33.3)$ & \\
\hline $1 / 1280$ & 49 (35.2) & $16(25.4)$ & \\
\hline$>1 / 1280$ & $19(13.8)$ & $9(14.3)$ & \\
\hline \multicolumn{4}{|l|}{ STA titer ${ }^{* *}$} \\
\hline$<1 / 640$ & $21(15.1)$ & $46(73.1)$ & \multirow{2}{*}{0.001} \\
\hline$\geq 1 / 640$ & $118(84.9)$ & $17(26.9)$ & \\
\hline
\end{tabular}

${ }^{*}$ Mean $\pm S D .,{ }^{* *} \mathrm{n}, \%$ STA: standard tube agglutination test 
Only 11 patient blood, bone marrow aspirates or synovial fluid samples were cultured for Brucella spp. Overall, 4 of 12 (33.3\%) blood cultures obtained from eight patients were positive. Also, 2 bone marrow aspirates cultures from two patients and 1 synovial fluid samples culture from one patient were positive. In our study, no subtype was determined.

The frequency of the osteoarticular involvement of patients is shown in Table III. The most commonly found osteoarticular involvement in our patients was peripheral arthritis $(n=44$, $83 \%)$. The majority of the peripheral arthritis ( $n=$ $42,95.4 \%$ ) was monoarticular. Only two patients with peripheral arthritis had pauciarticular joint involvement (one patient had bilateral hip involvement, and one patient had bilateral knee involvement). The most commonly affected peripheral joints were the hip $(n=21,4.7 \%)$ and knee $(n=15,34.1 \%)$. Other less commonly affected joints included the ankle $(n=3,6.8 \%)$, wrist $(n=2,4.5 \%$, shoulder $(n=1,2.3 \%)$, elbow $(n=1,2.3 \%)$, and interphalangeal joints $(n=1$, $2.3 \%)$.

Table III. Distribution of sites of osteoarticular involvement of patients.

\begin{tabular}{lc}
\hline Osteoarticular involvement & $n(\%)$ \\
\hline Peripheral arthritis & $44(83)$ \\
Knee & $21(47.7)$ \\
Hip & $15(34.1)$ \\
Ankle & $3(6.8)$ \\
Wrist & $2(4.5)$ \\
Shoulder & $1(2.3)$ \\
Elbow & $1(2.3)$ \\
Interphalangeal joints & $1(2.3)$ \\
Sacroiliitis & $5(9.4)$ \\
Spondylitis & $3(5.7)$ \\
Osteomyelitis & $1(1.9)$ \\
\hline
\end{tabular}

The second most commonly found osteoarticular involvement in our patients was sacroiliitis ( $n=5,9.4 \%)$, which was unilateral in the majority of the patients $(n=4)$. In only one patient was the sacroiliitis bilateral. Three patients with osteoarticular involvement $(5.7 \%)$ had spondylitis, and all these had lumbar region involvement. Only one patient $(1.9 \%)$ had Brucella osteomyelitis of the right proximal tibia.

The mean age of patients with peripheral arthritis was lower than that of patients with sacroiliitis and spondylitis $(9.7 \pm 3.5$ years, 13.4 \pm 5.3 years, respectively, $p=0.01$ ). Among the patients with peripheral arthritis, the mean age of patients with knee arthritis was lower than that of other patients $(8.23 \pm 3.7$ years, $11.7 \pm 3.6$ years, respectively, $p=0.02$ ). Also, the mean age of patients with hip arthritis was higher than that of patients with other joint involvement; however, this difference was not statistically significant $(11.4 \pm 2.8$ years, $9.89 \pm 4.4$ years, respectively, $p=0.13)$. Gender distribution rates for the various types of osteoarticular involvement were similar $(p=$ 0.12). All of the patients with chronic disease $(n=3)$ had osteoarticular involvement. Among these patients, two had sacroiliitis, and one had spondylitis.

The patients were treated with various antimicrobial combinations: oral rifampin, oral doxycycline in children $\geq 8$ years old, oral trimethoprim/sulfamethoxazole, intramuscular streptomycin, and intramuscular/intravenous gentamicin. Twenty-seven patients (50.9\%) with osteoarticular involvement received dual combination therapy (15 patients received trimethoprim-sulfamethoxazole and rifampicin, 12 patients received doxycycline and rifampicin) and 125 patients (83.9\%) without osteoarticular involvement received dual combination therapy (72 patients received trimethoprim-sulfamethoxazole and rifampicin, 53 patients received doxycycline and rifampicin). Twenty-six patients (49.1\%) with osteoarticular involvement received triple combination therapy (11 patients received trimethoprim-sulfamethoxazole and rifampicin and gentamicin or streptomycin, 15 patients received doxycycline and rifampicin and gentamicin or streptomycin) and 24 patients (16.1\%) without osteoarticular involvement received triple combination therapy (14 patients 
received trimethoprim-sulfamethoxazole and rifampicin and gentamicin or streptomycin, 10 patients received doxycycline and rifampicin and gentamicin or streptomycin). In the patients who had brucellosis without osteoarticular involvement, the triple combination therapy regime were used in complex cases of focal brucellosis such as neurobrucellosis, endocarditis or localized suppurative lesions and refractory diseases. In patients with osteoarticular involvement, the use of triple combination therapy was more common than patients without involvement $(p=0.001)$. In patients with osteoarticular involvement, the mean duration of treatment was $7.87 \pm 2.98$ weeks; this time interval was $7.05 \pm 0.0 .95$ weeks in patients without osteoarticular involvement. This difference was statistically significant $(p=0.006)$. In patients with spondylitis, osteomyelitis, or therapeutic failure, the duration of treatment was from 12 up to 24 weeks. The frequency of treatment failure and relapse was not significantly different between patients with and without osteoarticular involvement (overall, $p>0.05$ ) (Table IV).

\section{Discussion}

In this study, we found that osteoarticular involvement was present in $26.5 \%$ of childhood brucellosis cases. Studies have shown that the frequency of osteoarticular involvement in childhood brucellosis ranged from $6 \%$ to $75 \%$ in various regions of the world. ${ }^{6,9,14-21}$ Brucellosis remains a significant public health problem, and studies from different districts showed that this rate ranges from $6.7 \%$ to $73.5 \%$ in Turkey, as was also found in our study.,22-25 In these studies, which were comprised of childhood and adult groups, osteoarticular involvement in brucellosis was found more frequently in adults than in children. ${ }^{6,17}$ However, contrary to all these results, osteoarticular involvement in childhood was reported more in pediatric patients in one study from Turkey. ${ }^{7}$ In a different study, osteoarticular involvement was found to be more likely in patients from 15 to 45 years of age. ${ }^{10}$

In some studies, osteoarticular involvement in childhood brucellosis was reported to be more common in males. ${ }^{20,26,27}$ However, there are a few studies which reported it to be more common in females. ${ }^{9,14}$ In our study, there was no gender difference between patients with or without osteoarticular involvement. A few studies reported that osteoarticular involvement increases with age and is especially low in infants. ${ }^{12,20,26,27}$ Similarly to the results of these studies, patients with osteoarticular involvement were older than those without involvement in our study.

The routine screening of family members of index cases is a priority in endemic areas. However, in this study, family screening was not performed in all cases. Brucellosis is a multisystem disorder with unspecified clinical symptoms and findings. In our study, however, patients with osteoarticular involvement presented more frequently with fever, malaise, arthralgia, and myalgia than patients without involvement. Thus, the patients with osteoarticular involvement had more frequent complaints. Fever was the most frequent finding in other studies in patients with osteoarticular involvement. ${ }^{9,12,20,26}$ Contradictory

Table IV. Duration of treatment and frequencies of therapeutic failure and relapse of patients with and without osteoarticular involvement.

\begin{tabular}{lccc}
\hline & $\begin{array}{c}\text { Patients with } \\
\text { osteoarticular involvement }\end{array}$ & $\begin{array}{c}\text { Patients without } \\
\text { osteoarticular involvement }\end{array}$ & $p$-value \\
\hline Duration of treatment (weeks) $^{*}$ & $7.87 \pm 2.98$ & $7.05 \pm 0.95$ & 0.003 \\
Therapeutic failure** $^{*}$ & $2(3.8)$ & $5(3.4)$ & 0.88 \\
Relapse $^{* *}$ & $5(9.4)$ & $11(7.4)$ & 0.63 \\
\hline
\end{tabular}

${ }^{*}$ Mean $\pm S D .,{ }^{* *} \mathrm{n}(\%)$ 
to other reported studies ${ }^{9,12,20,26,28}$, there were no differences in the frequency of hepatomegaly and splenomegaly in brucellosis patients with osteoarticular involvement.

In our study, the most important abnormal laboratory findings were high-level ESR, C-RP, and leukocytosis. In the literature, high-level sedimentation rate and lymphocytosis were the most reported findings in childhood patients with osteoarticular involvement. ${ }^{7,20,26,27}$ On the other hand, in some studies, leucopenia, leukocytosis, thrombocytopenia, high liver enzyme level, and a high C-RP were more frequently reported findings in patients with osteoarticular involvement. ${ }^{9,12,14,20,27}$

In previous studies, correlations were shown between a high standard Wright agglutination level and disease severity. ${ }^{29,30}$ However, other studies reported that there were no significant differences between the standard Wright agglutination titers of patients with and without

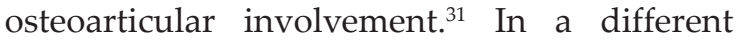
study, osteoarticular diagnosis involvement in brucellosis was verified in $98.7 \%$ of the patients via serologic tests, and three of the patients were reported as seronegative. ${ }^{32}$ In our study, the patients with osteoarticular involvement showed a higher-level standard Wright agglutination titer than those patients without osteoarticular involvement.

Osteoarticular involvement in childhood brucellosis is mostly seen as peripheral arthritis, specifically monoarticular in character, as reported in most studies. The frequency of peripheral arthritis in these studies ranged from $6.4 \%$ to $90 \%$. ${ }^{6,9,12,14,20,22,26,33,34}$ The most involved joints were the hip, knee, and ankle. ${ }^{9,10,14,18,20,33}$ In a few studies, the hip was the most frequently reported involved joint ${ }^{9,10,19,28,33}$; in others, the knee was the most often reported involved joint. ${ }^{20,35}$ Contradictory to these studies, Gómez-Reino et al. ${ }^{14}$ reported the most involved joint was the ankle. In the literature, minor joint involvement was rarely reported in brucellosis. ${ }^{35}$ In our study, we found that the most osteoarticular involvement was peripheral arthritis in children with brucellosis; this supports the findings of other studies. The most involved joints were the hip and knee, respectively, and these were monoarticular in nature. The other affected joints were the ankle, wrist, shoulder, elbow, and interphalangeal joints.

Sacroiliitis was the most reported clinical form of osteoarticular involvement in adult type brucellosis. ${ }^{5,10}$ In the literature, this form was reported at various frequencies, and it was generally unilateral in the pediatric age group with brucellosis. ${ }^{910,14,26}$ Gómez-Reino et al. ${ }^{14}$ reported $4.8 \%$, Al-Eissa et al. ${ }^{9}$ reported $8 \%$, and Bosilkovski et al. ${ }^{26}$ reported $6.8 \%$ in their studies. Contrary to this reported low frequency of sacroiliitis, Geyik et al. ${ }^{10}$ reported that sacroiliitis was diagnosed in $48.7 \%$ of the child and $62.2 \%$ of the adult patients with brucellosis. In our study, sacroiliitis was diagnosed in $9.4 \%$ of the osteoarticular involvement patients with brucellosis, and this involvement was generally $(80 \%)$ unilateral in form. On the other hand, all of the patients who had a sacroiliitis diagnosis were more than 11.5 years of age. Also, patients with sacroiliitis were older than patients with peripheral arthritis in accordance with findings in other studies. ${ }^{9,26,27}$

The other form of the osteoarticular involvement in brucellosis is spondylitis, and it generally increases in frequency in the fourth and fifth decades of adulthood. ${ }^{10,36,37}$ In several studies, spondylitis was very low in frequency, or there was no report of it in the pediatric age group with brucellosis., ${ }^{96,38}$ In our study, spondylitis was diagnosed in only three $(5.7 \%)$ patients with osteoarticular involvement in brucellosis. Moreover, osteomyelitis has been a rarely reported form for such patients..$^{9,21,35,39}$ In several osteoarticular brucellosis studies, osteomyelitis was not detected., ${ }^{70,14,26}$ In our study, only one patient was diagnosed with osteomyelitis.

Patients with spondylitis and sacroiliitis were older than patients with peripheral arthritis. The mean age of patients with knee involvement was significantly lower in peripheral arthritis 
patients. Although the mean age of the patients with hip involvement was higher than other peripheral arthritis patients' mean age, this finding was not statistically significant. Also, osteoarticular involvement was frequently found in subacute and chronic brucellosis patients. Even sacroiliitis was detected in two and spondylitis was detected in one of the three chronic brucellosis patients.

Sequelae are very rare in osteoarticular brucellosis. Avascular necrosis of the femur head and functional disability of the hip joints were the most reported sequelae., ${ }^{9,140}$ In our study, only one case of avascular necrosis of the femur head was detected.

The current study showed that osteoarticular involvement is a significant part of the multisystemic involvement in childhood brucellosis. In our study, osteoarticular involvement was detected in nearly one of every four childhood brucellosis patients. The most prominent form of the osteoarticular involvement was peripheral arthritis. The age of the patients with osteoarticular involvement and patients with sacroiliitis and spondylitis were older than patients with peripheral arthritis. Otherwise, the patients with osteoarticular involvement had more frequent complaints and higher ESR, C-RP, and STA levels. Additionally, brucellosis should be considered as a pre-diagnosis in children with osteoarticular complaints, especially in regions where the disease is endemic.

\section{Acknowledgments}

We are grateful to Efgan Gayyurhan and the children with brucellosis who volunteered to be part of this study.

\section{REFERENCES}

1. Pappas G, Papadimitriou P, Akriditis N, Christou $\mathrm{L}$, Tsianos EV. The new global map of human brucellosis. Lancet Infect Dis 2006; 6: 91-99.
2. Colmenero JD, Reguera JM, Martos F, et al. Complications associated with Brucella melitensis infection: a study of 530 cases. Medicine (Baltimore) 1996; 75: 195-211.

3. Republic of Turkey, Ministry of Health, Brucellosis statistical data for 1970-2004.

4. Kılıç S, Ivanov IN, Durmaz R, et al. Multiplelocus variable-number tandem-repeat analysis genotyping of human Brucella isolates from Turkey. J Clin Microbiol 2011; 49: 3276-3283.

5. Young EJ. Brucella species (Brucellosis). In: Long SS, Pickering LK, Prober CG (eds). Principles and Practice of Pediatric Infectious Diseases. (4th ed). New York: Elsevier, 2012: 861-865.

6. Al Shaalan M, Memish ZA, Al Mahmoud S, et al. Brucellosis in children: clinical observations in 115 cases. Int J Infec Dis 2002; 6: 182-186.

7. Gür A, Geyik MF, Dikici B, et al. Complications of brucellosis in different age groups: a study of 283 cases in southeastern Anatolia of Turkey. Yonsei Med J 2003; 44: 33-44.

8. Kennedy JC. Notes on case of chronic synovitis, or bursitis, due to organism of Mediterranean fever. J Roy Army Med Corps 1904; 2: 178-180.

9. Al-Eissa YA, Kambal AM, Alrabeeah AA, Abdullah AM, al-Jurayyan NA, al-Jishi NM. Osteoarticular brucellosis in children. Ann Rheum Dis 1990; 49: 896-900.

10. Geyik MF, Gür A, Nas K, et al. Musculoskeletal involvement of brucellosis in different age groups: a study of 195 cases. Swiss Med Wkly 2002; 132: 98105.

11. Dashti AS, Karimi A. Skeletal involvement of Brucella melitensis in children: a systematic review. Iran J Med Sci 2013; 38: 286-292.

12. Benjamin B, Annobil SH, Khan MR. Osteoarticular complications of childhood brucellosis: a study of 57 cases in Saudi Arabia. J Pediatr Orthop 1992; 12: 801-805.

13. Case definitions for infectious conditions under public health surveillance. Centers for Disease Control and Prevention. MMWR Recomm Rep 1997; 46: $1-55$.

14. Gómez-Reino FJ, Mateo I, Fuertes A, Gómez-Reino JJ. Brucellar arthritis in children and its successful treatment with trimethoprim-sulphamethoxazole (co-trimoxazole). Ann Rheum Dis 1986; 45: 256-258.

15. Almuneef M, Memish ZA, Al Shaalan M, Al Banyan E, Al-Alola S, Balkhy HH. Brucella melitensis bacteremia in children: review of 62 cases. J Chemother 2003; 15: 76-80. 
16. Mousa AR, Muhtaseb SA, Almudallal DS, Khodeir SM, Marafie AA. Osteoarticular complications of brucellosis: a study of 169 cases. Rev Infect Dis 1987; 9: 531-543.

17. Gotuzzo E, Seas C, Guerra JG, et al. Brucellar arthritis: a study of 39 Peruvian families. Ann Rheum Dis 1987; 46: 506-509.

18. Mantur BG, Akki AS, Mangalgi SS, Patil SV, Gobbur RH, Peerapur BV. Childhood brucellosis--a microbiological, epidemiological and clinical study. J Trop Pediatr 2004; 50: 153-157.

19. Roushan MRH, Ahmadi SAA, Gangi SMS, Janmohammadi N, Amiri MJS. Childhood brucellosis in Babol, Iran. Trop Doct 2005; 35: 229231.

20. Zamani A, Kooraki S, Mohazab RA, et al. Epidemiological and clinical features of Brucella arthritis in 24 children. Ann Saudi Med 2011; 31: 270-273.

21. el-Desouki M. Skeletal brucellosis: assessment with bone scintigraphy. Radiology 1991; 181: 415-418.

22. Tanir G, Tufekci SB, Tuygun N. Presentation, complications, and treatment outcome of brucellosis in Turkish children. Pediatr Int 2009; 51: 114-119.

23. Parlak M, Akbayram S, Doğan $M$, et al. Clinical manifestations and laboratory findings of 496 children with brucellosis in Van, Turkey. Pediatr Int 2015; 57: 586-589.

24. Yoldas T, Tezer H, Ozkaya-Parlakay A, Saylı TR. Clinical and laboratory findings of 97 pediatric brucellosis patients in central Turkey. J Microbiol Immunol Infect 2015; 48: 446-449.

25. Çıraklı S, Karlı A, Şensoy G, Belet N, Yanık K, Çıraklı A. Evaluation of childhood brucellosis in the central Black Sea region. Turk J Pediatr 2015; 57: 123-128.

26. Bosilkovski M, Kirova-Urosevic V, Cekovska Z, et al. Osteoarticular involvement in childhood brucellosis: experience with 133 cases in an endemic region. Pediatr Infect Dis J 2013; 32: 815-819.

27. Alvarez de Bruego M, Gomez Reino FJ, Gomez Reino JJ. A long term study of 22 children with brucellar arthritis. Clin Exp Rheumatol 1990; 8: 609-612.
28. Lubani M, Sharda D, Helin I. Brucella arthritis in children. Infection 1986; 14: 233-236.

29. Issa H, Jamal M. Brucellosis in children in south Jordan. East Mediterr Health J 1999; 5: 895-902.

30. Benjamin B, Annobil SH. Childhood brucellosis in southwestern Saudi Arabia: a 5-year experience. J Trop Pediatr 1992; 38: 167-172.

31. Hashemi SH, Keramat F, Ranjbar M, Mamani M, Farzam A, Jamal-Omidi S. Osteoarticular complications of brucellosis in Hamedan, an endemic area in the west of Iran. Int J Infect Dis 2007; 11: 496-500.

32. Janmohammadi N, Roushan MRH. False negative serological tests may lead to misdiagnosis and mismanagement in osteoarticular brucellosis. Trop Doct 2009; 39: 88-90.

33. Galanakis E, Bourantas KL, LeveidiotouS, Lapatsanis PD. Childhood brucellosis in north-western Greece: a retrospective analysis. Eur J Pediatr 1996; 155: 1-6.

34. Al-Shamahy HA, Wright SG. A study of 235 cases of human brucellosis in Sana'a, Republic of Yemen. East Mediterr Health J 2001; 7: 238-246.

35. Shen MW. Diagnostic and therapeutic challenges of childhood brucellosis in a nonendemic country. Pediatrics 2008; 121: e1178-e1183.

36. Lifeso RM, Harder E, McCorkell SJ. Spinal brucellosis. J Bone Joint Surg Br 1985; 67: 345-351.

37. Nas K, Gür A, Kemaloğlu MS, et al. Management of spinal brucellosis and outcome of rehabilitation. Spinal Cord 2001; 39: 223-227.

38. al-Eissa YA, Kambal AM, al-Nasser MN, alHabib SA, al-Fawaz IM, al-Zamil FA. Childhood brucellosis: a study of 102 cases. Pediatr Infect Dis J 1990; 9: 74-79.

39. Logan LK, Jacobs NM, McAuley JB, Weinstein RA, Anderson EJ. A multicenter retrospective study of childhood brucellosis in Chicago, Illinois from 1986 to 2008. Int J Infect Dis 2011; 15: e812-e817.

40. Benjamin B, Khan MR. Hip involvement in childhood brucellosis. J Bone Joint Surg Br 1994; 76: 544-547. 